Boise State University

ScholarWorks

$1-4-2006$

Applying Reflection Tomography in the Postmigration Domain to Multifold Ground-Penetrating Radar Data

John H. Bradford

Boise State University 


\title{
Applying reflection tomography in the postmigration domain to multifold ground-penetrating radar data
}

\author{
John H. Bradford ${ }^{1}$
}

\begin{abstract}
Acquisition and processing of multifold groundpenetrating radar (GPR) data enable detailed measurements of lateral velocity variability. The velocities constrain interpretation of subsurface materials and lead to significant improvement in image accuracy when coupled with prestack depth migration (PSDM). Reflection tomography in the postmigration domain was introduced in the early 1990s for velocity estimation in seismic reflection. This robust, accurate method is directly applicable in multifold GPR imaging. At a contaminated waste facility within the U.S. Department of Energy's Hanford site in Washington, the method is used to identify significant lateral and vertical velocity heterogeneity associated with infilled waste pits. Using both the PSDM images and velocity models in interpretation, a paleochannel system that underlies the site and likely forms contaminant migration pathways is identified.
\end{abstract}

\section{INTRODUCTION}

Accurate estimation of electromagnetic (EM) velocity from ground-penetrating radar (GPR) data enables accurate timeto-depth image transforms; in addition, velocity is an electrical property that can improve our understanding of the subsurface. When coupled with a suitable mixing equation, velocity can be used to estimate permittivity, which in turn may lead to estimates of pore-fluid content (Topp et al., 1980; Brewster and Annan, 1994; Greaves et al., 1996; Powers and Olhoeft, 1996; Huisman et al., 2003).

Most GPR surveys are acquired with a constant transmitterreceiver $\left(T_{x}-R_{x}\right)$ offset. EM velocity estimates can made be from these common-offset data with one of two methods. The first method utilizes qualitative interpretation to correlate reflectors in the radar section with significant boundaries iden- tified in the borehole data. However, there are drawbacks: Borehole data are not always available, there is potential for misinterpretation or misalignment, and this method suffers from a lack of lateral resolution. The second method of velocity estimation utilizes the moveout of scattering diffractions (Bradford and Harper, 2005), but the distribution of scattering events limits the precision of the velocity model, and often diffractions are not present.

It is typical to acquire one or more sparsely located CMP gathers within a broader GPR survey area to obtain a 1D or coarse laterally varying velocity structure for interpreting a common-offset survey. From the CMP gather, an rms velocity distribution is estimated using normal moveout (NMO) analysis (Campbell et al., 1995; Bradford et al., 1996; Young and Sun, 1996). A common strategy for computing effective interval velocities from the rms velocity incorporates Dix inversion (Dix, 1955). This approach does not account for lateral velocity heterogeneity and is sensitive to velocity errors resulting from dipping reflections or diffraction tails (Yilmaz, 2001).

Several published studies have overcome these limitations by acquiring multifold profiles (Fisher et al., 1992a; Liberty and Pelton, 1994; Pipan et al., 1999; Deeds and Bradford, 2002; Bradford, 2003, 2004; Pipan et al., 2003). With this method, the well-established acquisition geometries of seismic exploration are used to acquire multiple source/receiver offsets at each point within a survey. Multifold acquisition and processing in GPR imaging has a number of advantages, including suppression of coherent noise through dip-filtering methods and suppression of both coherent and random noise through stacking.

Although multifold data enable detailed measurement of lateral velocity variability (Greaves et al., 1996), NMO-based processing schemes are subject to the fundamental assumptions of NMO velocity analysis, which include small offsetto-depth ratios, small vertical and horizontal velocity gradients, and planar flat-lying reflections (Al-Chalabi, 1973, 1974; Yilmaz, 2001). These assumptions are often violated in GPR investigations (Deeds and Bradford, 2002; Bradford, 2003, 2004).

\footnotetext{
Manuscript received by the Editor December 12, 2004; revised manuscript received May 3, 2005; published online January 4, 2006.

${ }^{1}$ Boise State University, Center for Geophysical Investigation of the Shallow Subsurface, 1910 University Drive, Boise, Idaho 83725. E-mail: johnb@cgiss.boisestate.edu.

(C) 2006 Society of Exploration Geophysicists. All rights reserved.
} 


\section{REVIEW OF PRESTACK DEPTH MIGRATION VELOCITY ESTIMATION}

As with poststack migration and prestack time migration, prestack depth migration (PSDM) focuses scattered energy and moves dipping events to the correct spatial location. The primary advantage of PSDM is correct treatment of lateral and vertical velocity gradients. As long as precise amplitude reconstruction is not a primary interest (e.g., we are only measuring wavefield kinematics) and with the basic assumption that the subsurface electric properties are independent of frequency, many of the migration algorithms developed for seismic data analysis can be applied directly to GPR data without modification. While not generally true, the assumption of frequency-independent material properties is a reasonable first-order approximation in most cases, and often good migration results are obtained with any of the standard migration tools (Fisher et al., 1992a; Fisher et al., 1992b; Bradford et al., 1996; Bradford and Loughridge, 2003; Pipan et al., 2003; Bradford and Harper, 2005).

PSDM depends strongly on the depth-velocity model, so accurate velocity estimation is critical. Methods for estimating velocity distribution fall into two categories: reflection tomography and PSDM velocity analysis.

Table 1. Typical work flow for reflection tomography in the postmigration domain.

\begin{tabular}{|c|c|}
\hline Step & Procedure \\
\hline 1 & Derive starting depth-velocity model. \\
\hline 2 & Apply PSDM. \\
\hline 3 & Pick horizons. \\
\hline 4 & $\begin{array}{l}\text { Estimate wavefront kinematics using ray } \\
\text { tracing. }\end{array}$ \\
\hline 5 & $\begin{array}{l}\text { Estimate RMO distribution using } \\
\text { semblance analysis along coherent } \\
\text { horizons. }\end{array}$ \\
\hline 6 & Update velocity model via tomography. \\
\hline 7 & $\begin{array}{l}\text { Quality check/edit velocity model and } \\
\text { apply PSDM with new velocity model. }\end{array}$ \\
\hline 8 & $\begin{array}{l}\text { Quality check RMO distribution and } \\
\text { iterate starting at step } 3 \text { if necessary. }\end{array}$ \\
\hline
\end{tabular}
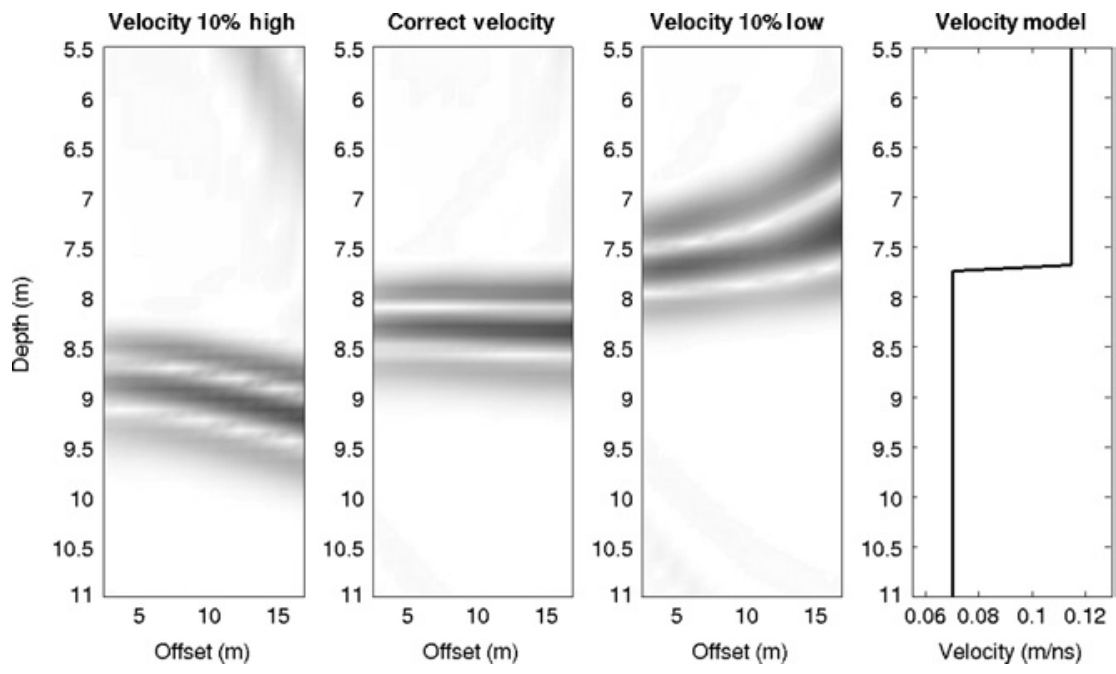

Figure 1. PSDM CIP gathers computed from a simple synthetic data set. RMO in the CIP gathers is strongly sensitive to even small errors in the velocity model.
Most tomography algorithms are designed to invert for the velocity structure based on traveltime picks of specific reflecting horizons in the premigration domain. As pointed out by Stork (1992), tomography has the advantage that computational methods for solving the inverse problem are well understood and solutions can be found quickly and efficiently. A significant disadvantage arises when there is significant subsurface complexity and wavefield distortion makes it difficult to pick the traveltimes of specific reflecting horizons.

PSDM velocity analysis takes advantage of the strong velocity dependence of PSDM. When the data are migrated with the correct velocity model, reflections in common-imagepoint (CIP) gathers (the postmigration analog of CMP gathers) migrate to the same depth and appear flat (Figure 1). If the velocity model is wrong, reflectors are not flat lying; this apparent offset-dependent depth is defined as residual moveout (RMO). RMO shows increasing depth with offset if the velocity is too high or decreasing depth with offset if the velocity is too low (Figure 1). After migration with an initial velocity model, the velocity model is updated iteratively to remove residual moveout with a top-to-bottom method known as layer stripping. With this method the data are remigrated after each velocity update and checked for RMO, often using coherence panels in the CIP domain (Lafond and Levander, 1993). PSDM analysis takes advantage of reflector coherence and continuity in the postmigration domain. This improves the processor's ability to evaluate specific reflecting horizons, particularly in a complex subsurface setting. Further, the output of PSDM velocity analysis are a subsurface velocity model and PSDM image.

Both reflection tomography and PSDM velocity analysis have been applied to GPR data. For example, Cai and McMechan (1999) describe a method for estimating the subsurface EM velocity and attenuation models using a reflection tomography algorithm. Leparoux et al. (2001) discuss the application of PSDM migration velocity analysis to GPR data, and Deeds and Bradford (2002) describe a case study taken from contaminated-site characterization.

Stork (1992) presents a method of reflection tomography that seeks to minimize RMO in CIP gathers in the postmigration domain. This method combines the computational advantages of tomography with the inherent interpretational advantage of PSDM velocity analysis. A code that utilizes Stork's method is available with Promax ${ }^{\mathrm{TM}}$ processing software, used to process all data in this study. A typical work flow for the application of this method is given in Table 1. Within this framework, detailed, conventional NMO/DMO processing is unnecessary. The approach is conceptually analogous to the image-processing stream posed by Rajasekaran and McMechan (1992) for seismic reflection data.

\section{FIELD APPLICATION: EXAMPLE FROM THE DOE HANFORD SITE}

The U. S. Department of Energy's Hanford site, located in southeast Washington (Figure 2), was integrally involved in 
World War II's Manhattan Project and produced much of the plutonium for the U.S. nuclear arsenal. These activities resulted in the release of large amounts of radiological and chemical waste to the environment at a number of locations throughout the Hanford complex (Department of Energy, 1998). The 618-10 burial ground is located approximately 4 miles northeast of Hanford's 300 area. This site contains several pits that received solid mixed waste from the mid 1950s until 1960 (Figure 2). The pits were later backfilled. During a surface stabilization project in 1983, a black, oily substance was observed bubbling to the surface above pit 4 . No samples were taken, but this substance is thought to be a potential contributor to groundwater contamination (DeFord et al., 1994). The 316-4 crib, located about 35 m southeast of 618-10 (Figure 2), consists of two buried, open-bottom tanks. Approximately 200000 liters of liquid organic and uranium wastes were pumped into the disposal tanks and allowed to drain into the underlying formation during the 1950s and 1960s. Radiological and volatile organic contamination has been found in several boreholes near the 618-10 and 316-4 sites (Bechtel, 1995; Department of Energy, 1997). Groundwater lies approximately $18 \mathrm{~m}$ below the surface, and there is concern that the observed radiological and chemical contamination will reach the groundwater and migrate to the Columbia River, located approximately $5 \mathrm{~km}$ to the east. Near-surface sediments at the site are comprised of surficial eolian sands ( $\sim-5 \mathrm{~m}$ depth) overlying the interbedded sands and gravels of the Hanford Formation ( 5-80 m depth) (Department of Energy, 1997).

This field campaign was undertaken as part of DOE's effort to identify and improve methods of quantitative geophysical characterization of contaminated sites, with a particular emphasis on developing detailed subsurface models at the Hanford site. One of the primary objectives in this study was imaging potential contaminant migration routes within the vadose zone beneath the 618-10 burial ground. In a 1997 cone-penetrometer (CPT) investigation, a low-permeability, cemented gravelly layer was identified at a depth of about $12 \mathrm{~m}$ and is suspected of playing a significant role in contaminant migration (Department of Energy, 1997). This cemented gravel was the primary target of the GPR investigation.

\section{Data acquisition and processing}

In September 2002, a field technician and I acquired $384 \mathrm{~m}$ of 2D multifold data, in common-source-point mode, along three profiles at the site (Figure 2). The acquisition procedure was similar to that described by Fisher et al. (1992a) using the parameters listed in Table 2. Common-source acquisition proved to be an efficient mode of operation over the irregular topography at the site, and all data were acquired in less than two days. Generally, data quality varied from excellent

a)

b)

c) to fair, with 150 to $200 \mathrm{~ns}(9-12 \mathrm{~m})$ of signal penetration (Figure 3). Departure from NMO was clearly evident in the common-source gathers (Figure 3A), indicating significant subsurface complexity.

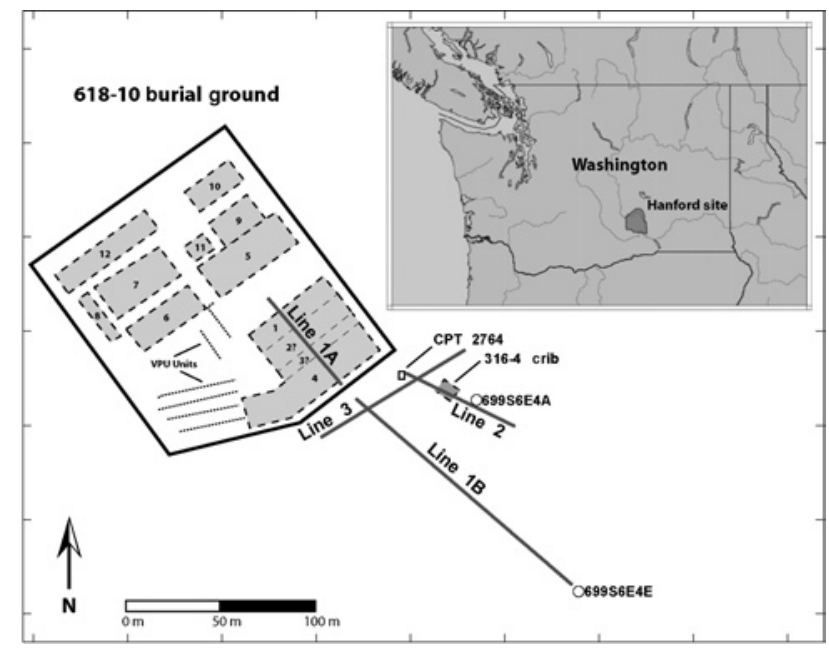

Figure 2. Site location and orientation of profiles discussed in the text.
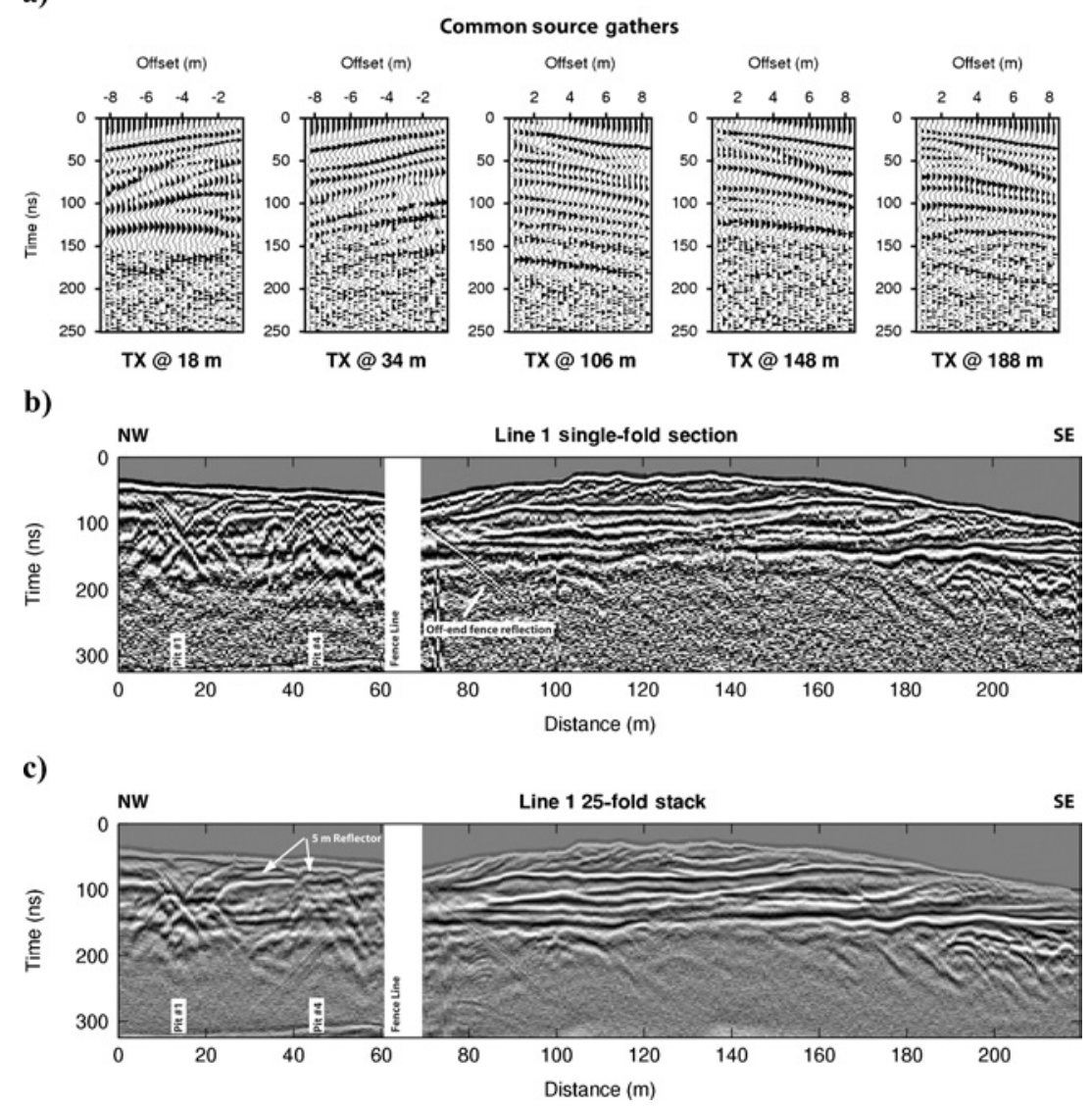

Figure 3. (a) Common-source gathers along lines $1 \mathrm{~A}$ (left) and 1B (right). (b) Conventional common-offset GPR section with a $0.61-\mathrm{m}$ trace spacing. (c) A 25 -fold, constant-velocity $(0.125-\mathrm{m} / \mathrm{ns})$ stack with $0.61-\mathrm{m}$ CMP bins. Significant departure from NMO in the source gathers at $T x=18 \mathrm{~m}$ and $T x=188 \mathrm{~m}$ suggests subsurface complexity. Stacking improves the $\mathrm{S} / \mathrm{N}$ ratio, most evident between 150 and $300 \mathrm{~ns}$ on the right-hand side of the profile. 
Premigration processing steps included a bandpass filter (12-25-200-400 MHz), automatic gain control (20-ns time gate), and construction of a starting depth-velocity model using sparse ( every $200 \mathrm{CMPs}) \mathrm{NMO}$ velocity analysis. A constant stacking velocity of $0.125 \mathrm{~m} / \mathrm{ns}$ produced a good stack with significant improvement in $\mathrm{S} / \mathrm{N}$ ratio over the conventional common-offset image (Figure 3). This improvement in data quality is particularly evident along the southeastern end of line 1, where steeply dipping clinoforms infilling a buried palechannel are clearly evident in the stacked image

Table 2. Data acquisition parameters.

\begin{tabular}{ll}
\hline Survey type & $\begin{array}{c}\text { Transverse electric, constant } \\
\text { azimuth } \\
\text { Sensors and software, Pulse EKKO } \\
100-\mathrm{A}, 100-\mathrm{MHz} \text { unshielded } \\
\text { antennas }\end{array}$ \\
GPR system & $\begin{array}{l}0.91 \mathrm{~m} / 8.2 \mathrm{~m} \\
\text { Min/max offset }\end{array}$ \\
No. receivers/source & 25 \\
Source interval & $0.61 \mathrm{~m}$ \\
Receiver interval & $0.30 \mathrm{~m}$ \\
Sampling interval & $0.8 \mathrm{~ns}$ \\
Recording time & $400 \mathrm{~ns}$ \\
No. stacks/source & 16 \\
\hline
\end{tabular}

a)

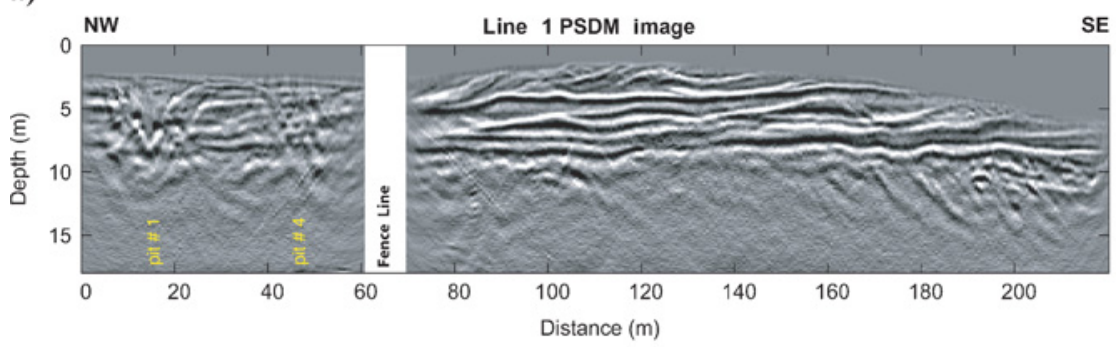

b)

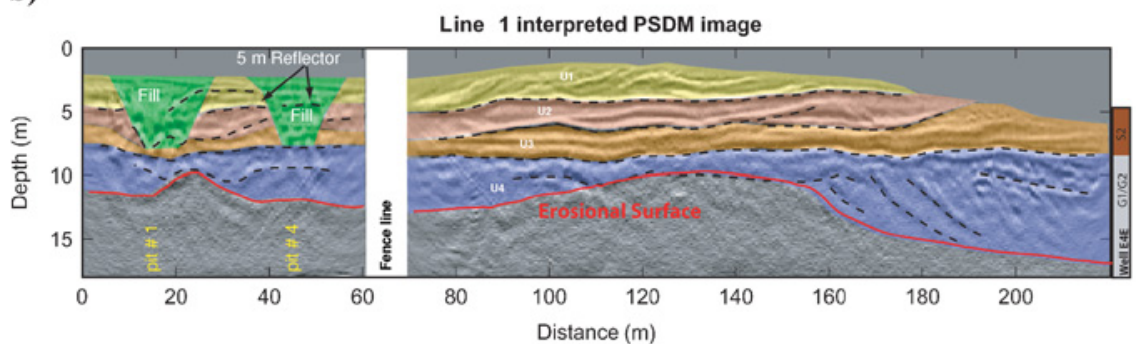

c)

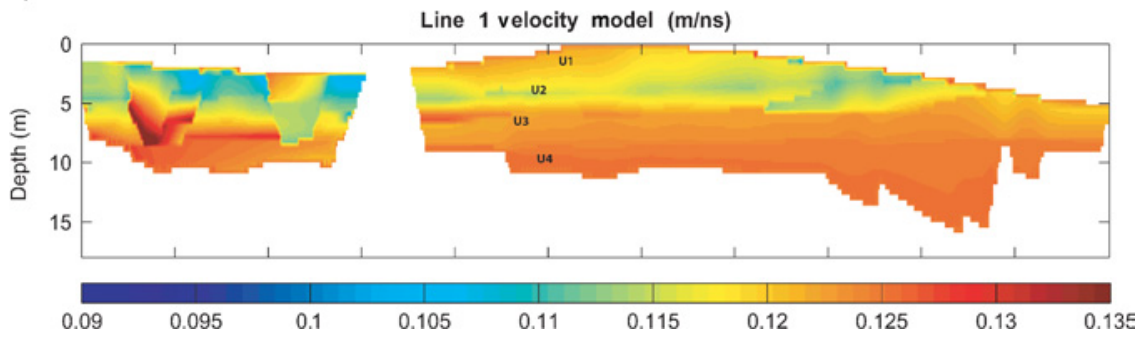

Figure 4. (a) PSDM image of line 1, (b) Interpretation of (a), and (c) tomographic velocity model. Horizons used for RMO analysis are indicated with dashed lines. The velocity model is shown only where there is ray coverage. The erosional surface at the base of U4 likely delineates a primary contaminant transport route. Pits 1 and 4 are clearly evident in both the reflection image and the velocity model. The cemented gravel unit was encountered in well E4E at a depth of $23 \mathrm{~m}$ b.d. but are difficult to identify in the common-offset image. Additionally, coherent noise resulting from an offend reflection from the chain-link fence is present in the common-offset section. In the CMP gathers, this coherent noise appears as a horizontal event and is strongly attenuated after NMO and

\section{Reflection tomography and PSDM}

The starting depth-velocity model was constant $(0.125 \mathrm{~m} / \mathrm{ns})$. Data were migrated in the common-offset domain using a Kirchhoff PSDM algorithm that includes topography. Note that the datum used for migration is the ground surface at well 699-S6-E4A (Figure 2). I picked eight or more horizons analysis along each profile (Figures 4 and 5). RMO was computed using semblance analysis in the CIP domain. The first round of RMO analysis, using the horizon at approximately $7.5 \mathrm{~m}$ depth along line 1A (Figure 4), showed a significant velocity high associated with pit 1 and a velocity low associated with pit 4 (Figure 6). More subtle velocity anomalies were present throughout the data set. I constrained the tome allow linear vertical velocity gradients between major RMO horizons, arbitrary lateral velocity variations, and discontinuities across RMO horizons. Additionally, the tomographic solution was damped within one spread length $(8.2 \mathrm{~m})$ of the profile ends to minimize edge effects. A single iteration of reflection tomography with these constraints significantly reduced RMO throughout the data set and produced good-quality PSDM images (Figures 4, 5, and 7).

To illustrate the need for PSDM velocity analysis, consider CMP 320 (Figure 8) at $x=12 \mathrm{~m}$ along line $1 \mathrm{~A}$ (Figures 3 and 4 ). In addition to a large lateral velocity gradient across the spread length, this CMP contains reflections from the scatterer at $14 \mathrm{~m}$ and the steeply dipping sides of pit 1 . Dix inversion using the stacking velocity function results in a wildly erratic interval velocity function that is not an accurate representation of the subsurface. Reflection tomography produces a reasonable velocity function and good migration results (Figure 8). Note that the scattered energy in CMP 320 has been migrated out of this imaging point and is not present in CIP 320.

\section{Interpretation}

I have identified four major stratigraphic units within the survey area. Unit divisions are based on the strength and continuity of radar reflections bounding each unit. As an additional constraint on the interpretation, I use significant divisions in the velocity profile, although significant lateral velocity heterogeneity exists within each unit. Interpretation of the lithology is based on borehole logs from wells 699-S6-E4A and 699-S6-E4E and CPT borehole B2764 
(Figure 2), acquired as part of an earlier site investigation (Department of Energy, 1997). While the borehole logs lack significant detail in the lithologic description, three sand units are identified in the upper $7 \mathrm{~m}$ below datum (b.d.): A brown sand (S1), a black sand (S2), and a basalt sand (S3) (Figure 5). Below this is a thick, sandy gravel unit $(\mathrm{G} 1 / \mathrm{G} 2)$. In the radar sections, numerous reflectors are evident within each of these coarsely defined units that are likely caused by small grain-size changes resulting in water-content variability. In well E4E, the target cemented gravel layer was encountered at $23 \mathrm{~m}$ b.d. The cemented gravel is not noted in the E4A log. Further constraint on the depth-to-gravel unit is taken from CPT borehole B2764 where the cemented gravel was encountered at $14 \mathrm{~m}$ b.d.

a)

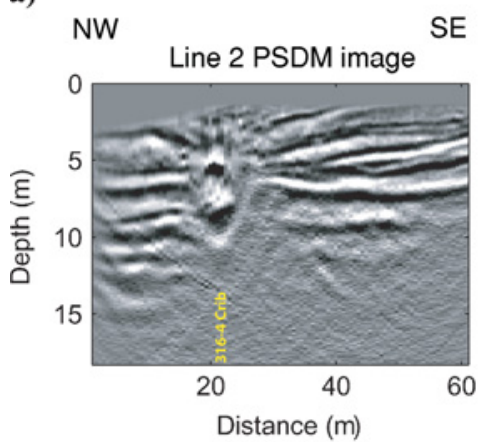

b)

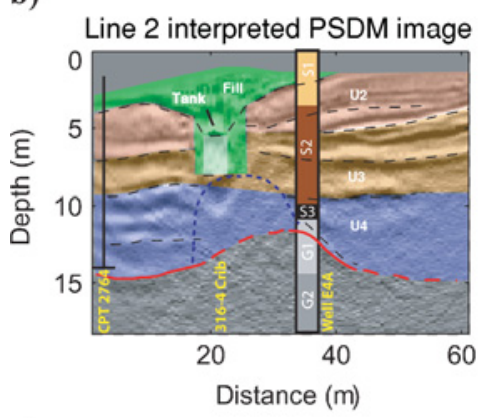

c)

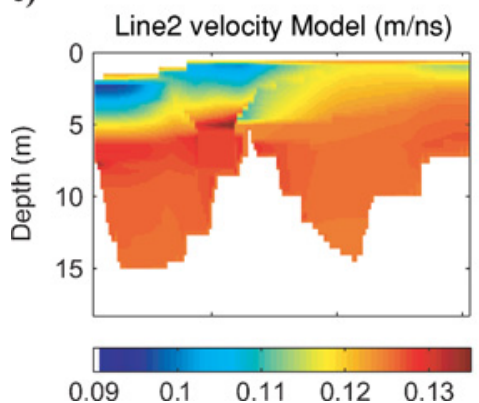

Figure 5. (a) PSDM image of line 2, (b) Interpretation of (a), and (c) tomographic velocity model. Horizons used for RMO analysis are indicated with dashed lines. The velocity model is shown only where there is ray coverage. One of the 316-4 crib disposal tanks is clearly delineated in the reflection section, but not the velocity model. Well E4A provides the most detailed available lithologic log over the depth of investigation. Depth to the cemented gravel unit in CPT B2764 was identified as the point of refusal.
The full stratigraphic profile is most clearly observed along line 1B (Figure 4) and line 3 (Figure 7) because the surface sediments along line 1A (Figure 4) and line 2 (Figure 5) were disturbed during waste disposal activities. The uppermost unit (U1) extends from 0 to about $4 \mathrm{~m}$ b.d.; $\mathrm{U} 1$ is comprised of the eolian sands that form the dune evident as a topographic high along line $1 \mathrm{~B}$ and line 2 . Unit 2 (U2) extends from about $4 \mathrm{~m}$ to nearly $6 \mathrm{~m}$ b.d. This unit is characterized by generally lower velocities. The velocity inversion associated with $\mathrm{U} 2 \mathrm{be}-$ comes more pronounced toward the southeastern boundary of the 618-10 burial ground where there is an areal topographic low. Unit 3 (U3) extends to a depth of approximately $8 \mathrm{~m}$, and the lower bounding horizon is an erosional discontinuity that marks the transition from the shallow sand-dominated system to the deeper gravel-dominated system. This surface appears to be approximately flat lying and planar throughout the survey area. U3 has generally higher velocities than U1 or U2. The U1-U3 package dips toward the southwest, with U2 reaching the surface at the northern portion of the survey area where U1 is not present (Figure 7). U4 is a sandy gravel unit that forms the fill of a paleochannel network that underlies the entire site. It varies in thickness from 0 to $>10 \mathrm{~m}$. U4 generally has the highest velocities observed at the site. Additionally, the base of U4 marks the maximum extent of radar-signal penetration.

In unsaturated sediments, velocity is primarily controlled by soil-moisture content (Topp et al., 1980; Olhoeft, 1986) with higher water content resulting in lower radar velocity. Finergrained materials tend to have higher residual water saturation from capillary forces (Bedient et al., 1994); it is reasonable to infer that in the vadose zone, low velocities correlate with finer-grained materials while higher velocities correlate with coarser-grained materials. Under this assumption I interpret U2 as composed of relatively fine-grained sand and U4 of relatively coarse material. While the available lithologic logs do not provide detailed grain-size estimates to confirm this interpretion, U4 is primarily a gravel unit, which is consistent with the interpretation.

Burial pits 1 and 4 are evident in the stacked image, where stratigraphic reflectors are truncated (Figure 3). Numerous scattering events from the base of the pits suggests buried debris covered with relatively homogeneous backfill. Burial pits 1 and 4 are clearly delineated in the PSDM image and inverted-velocity model (Figure 4). I found no evidence for pits 2 or 3 in either the velocity model or reflection

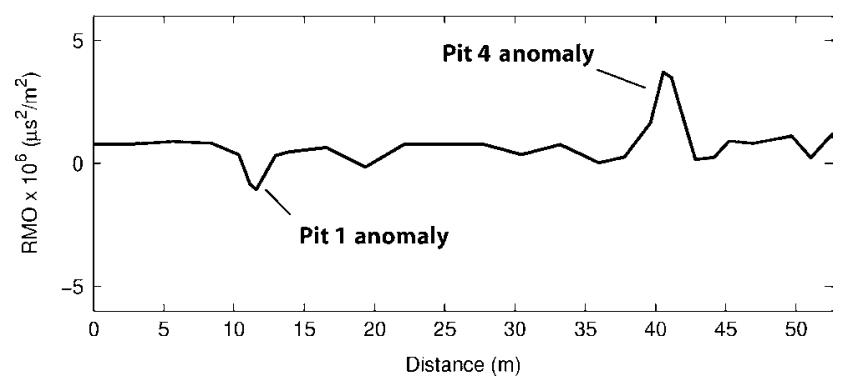

Figure 6. RMO along the horizon at approximately $7.5 \mathrm{~m}$ b.d., showing a high-velocity (negative RMO) anomaly associated with pit 1 and a low-velocity (positive RMO) anomaly associated with pit 4. 
images, suggesting that the positions of these pits were incorrectly mapped in the historical literature. Pit 1 has a large highvelocity anomaly associated with the buried debris located near the base of the pit. Pit 4 has a stratified velocity structure with a velocity high located within a fill layer at the top of the pit and a significant velocity low associated with the material filling the deeper portion of the pit. This is opposite the trend observed in the adjacent stratigraphic section, where the surface velocity is slow and then increases in the deeper strata. The trend in the velocity model is consistent with the observed reflectivity, where the 5-m-deep reflection within pit 4 has polarity opposite that of the adjacent 5-m-deep stratigraphic reflection (Figures 3 and 4).

a)

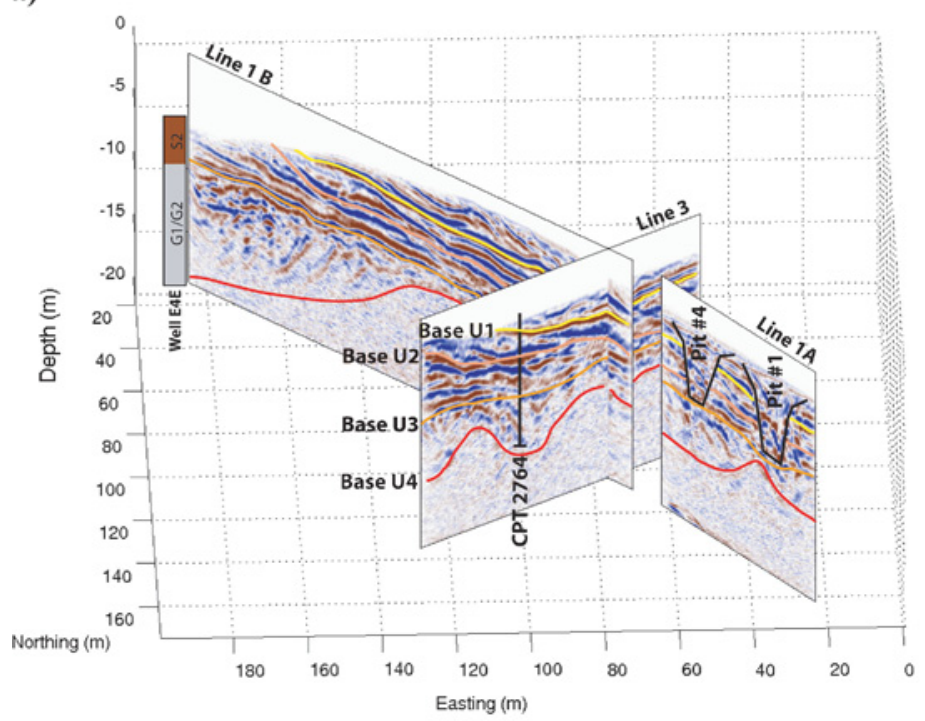

b)

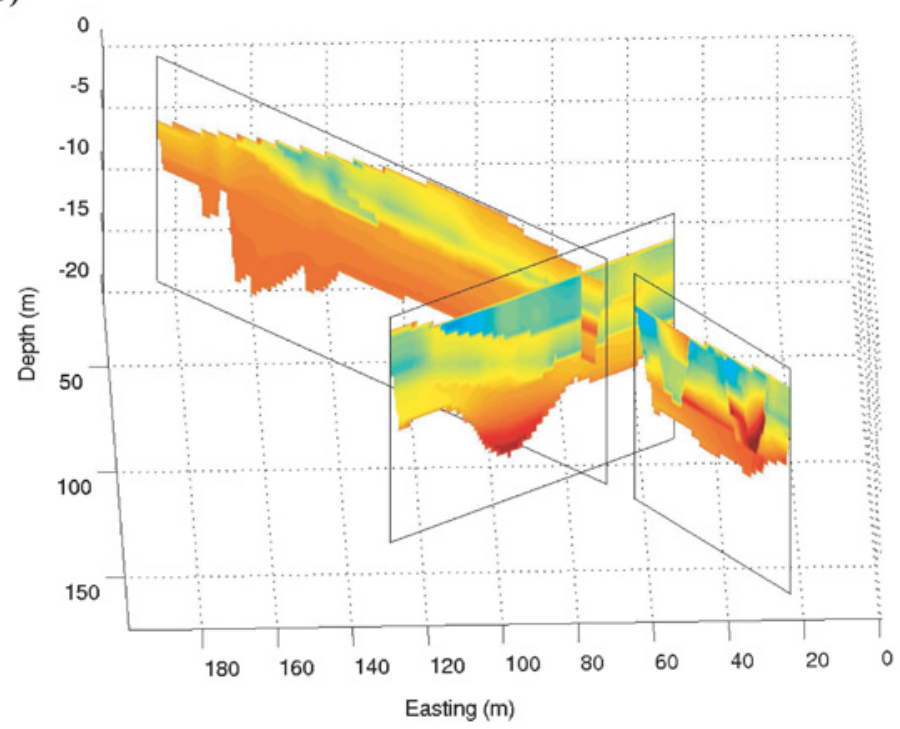

Figure 7. (a) PSDM reflection images of line 1 sand 3 and (b) tomographic velocity models. Based on high-radar-velocity and borehole observations, we interpret U4 to be comprised of relatively coarse-grained and likely high-permeability sandy gravels. The cemented gravel unit identified in CPT 2764 and well E4E appears to lie at the base of U4, which defines a northwest-southeast-trending paleochannel network that likely forms primary contaminant transport routes.

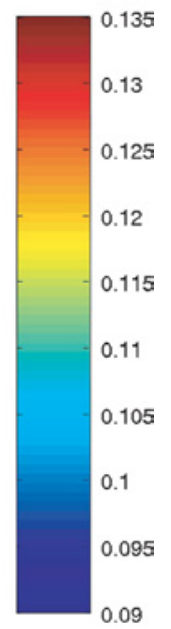

The disposal tank and disturbed surficial sediments associated with the 316-4 crib are clearly imaged in the PSDM section (Figure 5). Historical DOE records indicated that these were stainless steel tanks (Bergstrom et al., 1995), but this is necessarily incorrect as there is a clear radar image from both the top and bottom of the tank which would be impossible were it constructed from electrically conductive material. Surprisingly, there is no clear velocity anomaly associated with the tank itself (Figure 5), since I expect the empty tank to produce a high-velocity zone. It is important to note that the velocity of this feature is poorly constrained because there is no continuous horizon imaged below the tank and the dimensions of the tank are only about one wavelength (in air) at the dominant signal frequency. Of further interest is the zone of high attenuation that appears to emanate from the base of the disposal tank. This is likely caused by increased conductivity of the sediment column as a result of residual ion deposition from the dumped radiological contaminants.

As stated in the introduction, the primary objective of this study was to characterize the cemented gravel layer noted in an earlier DOE investigation (Department of Energy, 1997). The cemented gravel was encountered at about $14 \mathrm{~m}$ b.d. in CPT borehole B2764, which correlates with the erosional surface that forms the base of $\mathrm{U} 4$ along lines 2 and 3 (Figures 5 and 7). Additionally, the lithologic log from well 699S6-E4E, located just beyond the southeast end of line 1 , indicates that cemented gravel was encountered at about $23 \mathrm{~m}$ b.d.. This is roughly consistent with the base of U4, which reaches about $18 \mathrm{~m}$ b.d. at the southeastern end of line 1 and appears to continue deepening off the end of the profile. Note that precise interpretation of the base of U4 is difficult at this location because of very low reflection strength, and internal inconsistencies in the E4E lithologic $\log$ make its reliability questionable. Generally, however, I interpret the cemented gravel as lying at or just below the erosional surface that forms the paleochannel network at the base of U4. This is likely caliche, which typically forms just below exposure surfaces (American Geologic Institute, 1972; Blatt et al., 1972).

There are two significant problems to consider with the data set. First, the velocity models at the intersection of lines 1 and 3 are not in good agreement, although the general features are similar, i.e., U1, $\mathrm{U} 3$, and $\mathrm{U} 4$ are faster and $\mathrm{U} 2$ is slower. The intersection of these two profiles is very near the end of line $1 \mathrm{~B}$ in the region where the tomographic solution is damped. Also, there is a clear depositional trend toward the southeast, which may result in 

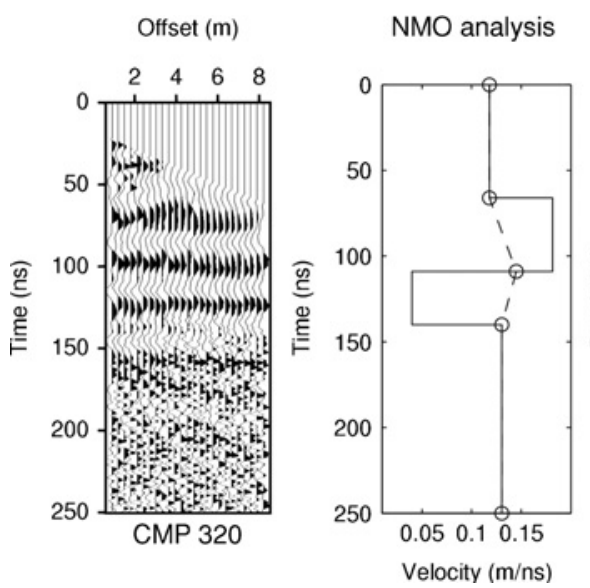

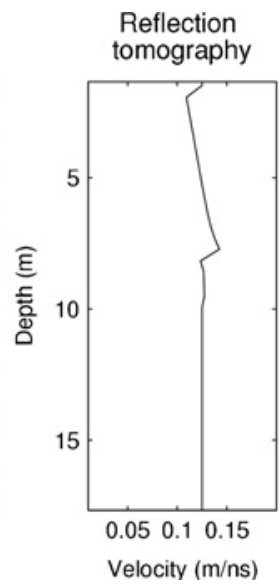

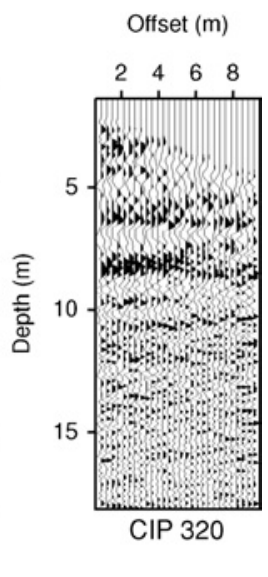

possible to accurately resolve significant lateral and vertical velocity heterogeneity. The resulting detailed velocity models could be interpreted directly to locate significant features such as the waste disposal pits within the 618-10 burial ground. Further, the velocity models helped to guide the interpretation of significant lithologic units and to constrain the likely relative grain-size distribution. Finally, the PSDM images, coupled with the detailed velocity models, identified a paleochannel network underlying the site as forming likely contaminant migration pathways.

\section{ACKNOWLEDGMENTS}

Figure 8. Comparison of the results of NMO analysis and reflection tomography at CMP $320(12 \mathrm{~m})$ on line $1 \mathrm{~A}$ (Figures 3 and 4). The trace at offset $-6 \mathrm{~m}$ with the transmitter at $18 \mathrm{~m}$ in Figure 3 corresponds to this CMP. The NMO-corrected CMP and migrated CIP are shown. The stacking velocity (dashed line) is a poor measure of the rms velocity at this CMP because of strong lateral velocity gradients, scattering from debris within the pit, and steeply dipping reflectors on the pit boundary. Dix inversion with this stacking velocity function is near the stability limit, resulting in erratic shifts in the interval velocity function (solid line). Reflection tomography produces a reasonable velocity function and good PSDM results. The reflection at 109 ns (negative peak) in CMP 320, from an adjacent scattering event, is migrated out of the imaging point and therefore is not present in CIP 320.

The U. S. Department of Energy funded this work under the Environmental Management Science Program, grant DEFG07-99ER15008. Boise State University acknowledges support of this research by Landmark Graphics Corp. via the Landmark University Grant Program.

\section{REFERENCES} tion where there is a significant lateral velocity increase along line 3 . The line 1 velocities will be preferentially biased toward the higher velocity zone. This leads directly to the second significant problem. The 3D complexity of both the stratigraphy and velocity structure means that the results of $2 \mathrm{D}$ analysis are contaminated with out-of-plane energy. This may only be resolved in detail through full 3D data acquisition and processing; however, generally good agreement between the PSDM images and available lithologic control provides a level of confidence in the general conclusions of the data interpretation.

My analysis shows that both the 618-10 burial ground and 316-4 crib are underlain by a paleochannel network that has a low-permeability cemented unit at its base. The channel fill, $\mathrm{U} 4$, consists of coarse-grained and likely high-permeability sands and gravels. It is probable that this paleochannel network forms a prime migration route for contaminants emanating from either the $618-10$ burial ground or the 316-4 crib.

\section{CONCLUSIONS}

Reflection tomography in the postmigration domain is an attractive tool for velocity analysis of multifold GPR data. It combines the computational efficiency of tomographic inversion with the practical advantages of data interpretation in the postmigration domain - specifically, semblance within CIP gathers and reflector coherence in horizon picking. As a further benefit, the output of the method is both a depth-velocity model and PSDM radar section.

The field example demonstrates the added benefit of CMO data acquisition and processing methodologies. CMP/CIP stacking significantly improved the $\mathrm{S} / \mathrm{N}$ ratio in the GPR sections, leading to more confident, detailed interpretation. Reflection tomography in the postmigration domain made it
Al-Chalabi, M., 1973, Series approximation in velocity and traveltime computations: Geophysical Prospecting, 21, 783-795.

,1974, An analysis of stacking, RMS, average, and interval velocities over a horizontally layered ground: Geophysical Prospecting, 22, 458-475.

American Geologic Institute, 1972, Glossary of geology: American Geological Institute. and organics at well \#699-S6-E4A: Bechtel Hanford report RLBHI-REMACT-1995-003.

Bedient, P. B., H. S. Rifai, and C. J. Newell, 1994, Ground water contamination: Transport and remediation: Prentice-Hall, Inc.

Bergstrom, K. A., T. H. Mitchell, and B. J. Bolin, 1995, Geophysical investigations of the 316-4 (300 north crib), the 618-8 burial ground, the 618-13 (mound), the undocumented solid waste burial ground, the solid waste burial ground (early burial ground), and the burial Hanford report BHI-00212.

Blatt, H., G. Middleton, and R. Murray, 1972, Origin of sedimentary rocks: Prentice-Hall, Inc.

Bradford, J. H., 2003, GPR offset-dependent reflectivity analysis for characterization of a high-conductivity LNAPL plume: Symposium on the Application of Geophysics to Environmental and Engineering Problems (SAGEEP), Environmental and Engineering Geophysical Society, Proceedings, 238-252.

, 2004, 3D Multi-offset, multi-polarization acquisition and processing of GPR data: A controlled DNAPL spill experiment: SymEngineering Problems (SAGEEP), Environmental and Engineering Geophysical Society, Proceedings, 514-527.

Bradford, J. H., and J. T. Harper, 2005, Wavefield migration as a tool for estimating spatially continuous radar velocity and water content in glaciers: Geophysical Research Letters, 32, L08502, doi:10.1029/2004GL021770.

Bradford, J. H., and J. Loughridge, 2003, Application of two-pass migration to 3D GPR data: Symposium on the Application of Geophysics to Environmental and Engineering Problems (SAGEEP), Environmental and Engineering Geophysical Society, Proceedings, 598-612.

Bradford, J., M. Ramaswami, and C. Peddy, 1996, Imaging PVC gas pipes using 3-D GPR: Symposium on the Application of Geophysics to Environmental and Engineering Problems (SAGEEP), Environmental and Engineering Geophysical Society, Proceedings, $519-524$.
Bechtel Hanford Inc., 1995, Unexpected radiological contamination trench west of the process trenches, 300-FF-2 operable unit: Bechtel posium on the Application of Geophysics to Environmental and 
Brewster, M. L., and A. P. Annan, 1994, Ground-penetrating radar monitoring of a controlled DNAPL release: $200 \mathrm{MHz}$ radar: Geophysics, 59, 1211-1221.

Cai, J., and G. A. McMechan, 1999, 2-D ray-based tomography for velocity, layer shape, and attenuation from GPR data: Geophysics, 64, 1579-1593.

Campbell, D. L., J. E. Lucious, K. J. Ellefson, and M. DeszczPan, 1995, Monitoring of a controlled LNAPL spill using groundpenetrating radar: Symposium on the Application of Geophysics to Environmental and Engineering Problems (SAGEEP), Environmental and Engineering Geophysical Society, Proceedings, 511517.

Deeds, J. C., and J. H. Bradford, 2002, Characterization of an aquitard and direct detection of LNAPL at Hill Air Force Base using GPR AVO and migration velocity analysis: 9th International Conference on Ground Penetrating Radar, International Society for Optical Engineering, Proceedings, 323-329.

DeFord, D. H., R. W. Carpenter, and M. W. Einan, 1994, 300-FF-2 operable unit technical baseline report: Bechtel Hanford report BHI-00012.

Department of Energy, 1997, Limited field investigation report for the 300-FF-2 operable unit: DOE/RL-96-42.

1998, Groundwater/vadose zone integration project specification: DOE/RL-98-48.

Dix, C. H., 1955, Seismic velocities from surface measurements: Geophysics, 34, 180-195.

Fisher, E., G. A. McMechan, and A. P. Annan, 1992a, Acquisition and processing of wide-aperture ground-penetrating radar data: Geophysics, 57, 495-504.

Fisher, E., G. A. McMechan, A. P. Annan, and S. W. Cosway, 1992b, Examples of reverse-time migration of single channel groundpenetrating radar profiles: Geophysics, 57, 577-586.

Greaves, R. J., D. P. Lesmes, J. M. Lee, and M. N. Toksoz, 1996, Velocity variation and water content estimated from multi-offset, ground-penetrating radar: Geophysics, 61, 683-695.

Huisman, J. A., S. S. Hubbard, J. D. Redman, and A. P. Annan, 2003, Measuring soil water content with ground-penetrating radar: A review: Vadose Zone Journal, 2, 476-491.

Lafond, C. F., and A. R. Levander, 1993, Migration moveout analysis and depth focusing: Geophysics, $\mathbf{5 8}, 91-100$.

Leparoux, D., D. Gibert, and P. Cote, 2001, Adaptation of prestack migration to multi-offset ground-penetrating radar (GPR) data: Geophysical Prospecting, 49, 374-386.

Liberty, L. M., and J. R. Pelton, 1994, A comparison of groundpenetrating radar methods: Multi-fold data vs. single fold data: 30 th Symposium on Engineering Geology and Geotechnical Engineering: Hydrogeology, Waste Disposal, Science and Politics, Proceedings, 321-324.

Olhoeft, G. R., 1986, Direct detection of hydrocarbon and organic chemicals with ground-penetrating radar and complex resistivity: Conference on Petroleum and Hydrocarbons and Organic Chemicals in Groundwater - Prevention, Detection, and Restoration, NWWA/API, Proceedings, 284-305.

Pipan, M., L. Baradello, E. Forte, A. Prizzon, and I. Finetti, 1999, 2-D and 3-D processing and interpretation of multi-fold ground penetrating data: A case history from an archaeological site: Journal of Applied Geophysics, 41, 271-292.

Pipan, M., E. Forte, M. Dal Moro, M. Sugan, and I. Finetti, 2003, Multifold ground-penetrating radar and resistivity to study the stratigraphy of shallow unconsolidated sediments: The Leading Edge, 22, 876-881.

Powers, M. H., and G. R. Olhoeft, 1996, Modeling the response of leaking, buried pipes: Application of Geophysics to Environmental and Engineering Problems, Environmental and Engineering Geophysical Society, Proceedings, 525-534.

Rajasekaran, S., and G. A. McMechan, 1992, A new approach to prestack seismic processing: 62nd Annual International Meeting, SEG, Expanded Abstracts, 1030-1033.

Stork, C., 1992, Reflection tomography in the postmigrated domain: Geophysics, 57, 680-692.

Topp, G. C., J. L. Davis, and A. P. Annan, 1980, Electromagnetic determination of soil water content; measurements in coaxial transmission lines: Water Resources Research, 16, 574-582.

Yilmaz, Ö., 2001, Seismic data analysis: Society of Exploration Geophysicists.

Young, R. A., and J. Sun, 1996, 3D ground penetrating radar imaging of a shallow aquifer at Hill Air Force Base, Utah: Journal of Environmental and Engineering Geophysics, 1, 97-108. 